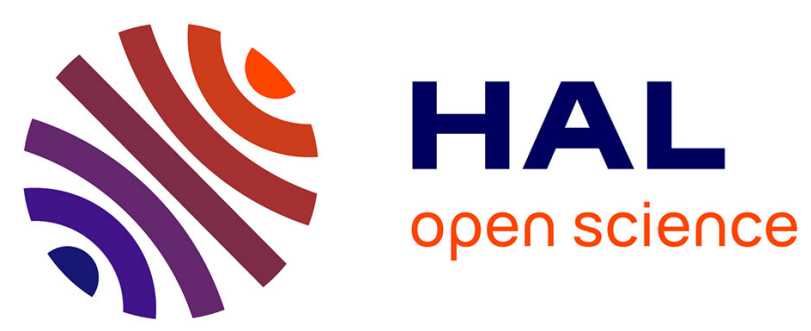

\title{
A 4pt Bending Bond Test Approach to Evaluate Water Effect in a Composite Beam
}

\author{
Armelle Chabot, Ferhat Hammoum, Manitou Hun
}

\section{To cite this version:}

Armelle Chabot, Ferhat Hammoum, Manitou Hun. A 4pt Bending Bond Test Approach to Evaluate Water Effect in a Composite Beam. European Journal of Environmental and Civil Engineering, 2017, Mechanisms of Cracking and Debonding in Pavements: debonding mechanisms in various interfaces between layers, 21 (s1), pp.54-69. 10.1080/19648189.2017.1320237 . hal-01552114

\section{HAL Id: hal-01552114 https://hal.science/hal-01552114}

Submitted on 30 Jun 2017

HAL is a multi-disciplinary open access archive for the deposit and dissemination of scientific research documents, whether they are published or not. The documents may come from teaching and research institutions in France or abroad, or from public or private research centers.
L'archive ouverte pluridisciplinaire HAL, est destinée au dépôt et à la diffusion de documents scientifiques de niveau recherche, publiés ou non, émanant des établissements d'enseignement et de recherche français ou étrangers, des laboratoires publics ou privés. 


\title{
A 4pt Bending Bond Test Approach to Evaluate Water Effect in a Composite Beam
}

\begin{abstract}
Considering that water may cause a separation of interfaces between layers of pavement structures, specific test on bi-layer specimens is performed in a water bath. For the study of the bond between layers made of cement concrete overlay on bituminous material, four-point bending results show a competition between different failure mechanisms. Actually a very good bond resistance between layers compared to the fracture tension resistance of the cement concrete layer is preliminary observed in dry conditions. In this work, first results of the water effect on the behaviour of such a material interface are presented. The final fracture length of the specimen and the corresponding curve of forcedisplacement highlight the influence of water immersion on the debonding failure mode. The field displacement measurement obtained by Digital Image Correlation (DIC) is used to improve the understanding of the fracture scenario.
\end{abstract}

Keywords: crack, debonding, four-point bending test, water effect, DIC, heterogeneous material

\section{Introduction}

Composite pavement systems, made of concrete/asphalt and asphalt/concrete structure, show good potential for being an interesting rehabilitation option for urban pavements that exhibit structural deterioration (De Larrard et al., 2005). However, due to shrinkage phenomenon of cement materials, the existing vertical crack combined to environmental and traffic loading lead to failures that may develop as delamination between layers (Pouteau et al., 2004) (Chabot et al., 2008). Typically, such debonding initiates and propagates under the combined influence of normal and shear stresses (Tran et al., 2004) (Chabot et al., 2004, 2005, 2007). The presence of water, whatever its phase is, adds to this complex phenomenon an irreversible damage that cannot be ignored (Vulcano-Greullet et al., 2010) (Vandenbossche et al., 2011) (Mauduit et al., 2010, 2013) (Raab et al., 2012) (Mateos at al., 2016). The damage can be driven with two mechanisms: (a) loss in strength and durability of materials due to the presence of water in the pore of asphalt concrete (b) loss of mechanical behaviour of bond between layers. Evaluating the effect of water on the interface behaviour is complex.

In order to investigate the mixed mode characterisation of such a bond between bi-layers in the pavement, an existing four-point bending test (4PB) has been adapted (Figure 1) (Hun, 2012). Two types of bi-layer interface are made with the same material layers (cement concrete and bituminous concrete). The first experimental results tested under controlled static conditions $(0.7 \mathrm{~mm} / \mathrm{min}$, ambient temperature), have shown that this approach is able to give a first idea on the interface resistance of the bond between two layers and of its treatment (Hun et al., 2012). The advantage of such a test is to be able to investigate the mechanical properties of interfaces under mixed mode conditions without using any supports nor applying any loads directly on the bituminous material. 
In the case of the UTW (UltraThin White-topping pavements) bi-layer specimens made of a cement concrete overlay (noted layer 2 on Figure 1) on bituminous material (noted layer 1 on Figure 1), first analyses at a macro scale level have lead to the conclusion that the UTW bond has a very good resistance in such a test compared to the fracture tension resistance of the cement concrete layer. Several final fractures of the specimens have occurred (Figure 2) in a similar way than for materials used in reinforced concrete (RC) beams or slabs from where this test is used (Teng et al., 2003). For the final fracture configuration of Figure $2 \mathrm{c}$, it is difficult, by visual observations and mechanical response expressed by the load displacement curve, to determinate if the debonding phenomenon occurs first or not compared to the final bending crack of the cement concrete layer (Chabot et al., 2013a).

In this paper, to improve the knowledge of the fracture scenario of bi-layer materials of such a 4PB test, the Digital Image Correlation (DIC) method is used (Sutton et al., 1983) (Roux et al., 2009). The work also aims to understand if water favours or not the debonding phenomenon at the interface between UTW pavement layers. The phenomenon of the cement shrinkage or other effects on bonding between a cement substrate and a layer such as studied in (Pérez et al., 2009) (Pan et al., 2010) for cement concrete materials are not considered here.

In the following sections, the theoretical elastic characterization of the bond during the $4 \mathrm{~PB}$ test is first briefly presented. Secondly, the characteristics of the materials tested are given and the preparation of the specimens is presented. Then several information of the experimental device is described before showing the result curves for the different test conditions. The fourth paragraph, with the help of the several DIC investigations and basic calculations, aims to propose a final fracture scenario of the specimens tested before concluding.

\section{Theoretical Characterization of the bond during the 4PB test}

A mechanical analysis of the design of the specimen has been performed (Hun et al., 2012). The calculation has been realized with the help of a multi-particular modelling approach developped for studying edge effect leading to the delamination of composite materials (Naciri et al., 1998) (Chabot 1997) (Chabot \& Ehrlacher, 1998). In such a layer-wise modelling of the structure, so-called M4 for multi-particle model of multilayer materials, the stress fields are defined by through polynomial approximations in the vertical direction for each layer i. The M4 offers the advantage of defining the out-of-interface plane normal $v^{i, i+1}$ and shear stresses $\tau^{i, i+1}$ at interface between layers $\mathrm{i}$ and $i+1$. The interface is supposed so to be a surface (that is to say with no thickness). These interface stresses have a physical meaning and represent the exact out-of-plane 3D stresses calculated at the interface between two layers. The evaluation of the mechanical fields is then obtained by using the Hellinger-Reissner variational principle (Reissner, 1950). It reduces the dimension of the problem that is especially convenient for computing 3D pavement solutions (Tran et al., 2004) (Chabot et al., 2004, 2005, 2007) (Nasser et al., 2016). As opposed to other classical models, the main interest of 
this modelling is to yield finite stresses at a free edge or crack tip at the interface point location of two different layers (Chabot, 1997). For the M4-5n with five kinematic fields per layer (n: total number of layers i) used here, the membranar stresses in each layer are written as first-order polynomials and shear and normal stresses are then obtained by integrating the 3D equilibrium equations. In the M4-5n, the multilayered structure is considered as a superposition of Reissner-Mindlin plates linked together by the interfacial stresses.

Applied to the $4 \mathrm{~PB}$ test under 2D plane strain assumptions with homogeneous, elastic and isotropic materials, the M4-5n solutions are given in a previous work with parametric calculations. Depending on ratio value of the Young modulus ratio of the two materials, the simulation indicates that a competition exists between tensile stress at the bottom of the cement concrete in layer 2 (between points B and C) and interface normal and shear stresses (at points A and D) (Figure 1). In order to obtain the debonding phenomenon between the two layers onto only one side, a non-symmetrical geometry of the specimens has been finally proposed. A higher geometrical value of $a_{1}$ length compared to the $a_{2}$ length one favours delamination on the side $a_{1}$ first (Figure 1). This anti-symmetrical specimen allows using the digital image analysis on one side of the specimen only (see $\S 4$ ). The interested reader should refer to (Chabot et al., 2013a) for a complete description of all the calculations.

On the following we denote $\mathrm{b}$ as the width of the beam. $\mathrm{e}^{\mathrm{i}}, \mathrm{E}^{\mathrm{i}}$ and $v^{i}$ are respectively the thickness, Young's modulus and Poisson's ratio of each layer i. Figure 3 illustrates, for a total load F of $4.2 \mathrm{~N}$, the M4-5n stress distribution in the bi-layer specimen made of the pavement materials tested in this study around $20^{\circ} \mathrm{C}$ $\left(\mathrm{E} 2 / \mathrm{E} 1 \approx 17.5 ; \boldsymbol{v}^{1}=0.30, \boldsymbol{v}^{2}=0.35, \mathrm{~L}_{\text {Total }}=480 \mathrm{~mm}\right.$ with $\mathrm{L}=420 \mathrm{~mm}$ between supports, $\mathrm{e} 1=\mathrm{e} 2=60 \mathrm{~mm}, \mathrm{~b}=100$ ). The Figure 3 gives the M4-5n interface distributions of the normal stress $v^{1,2}(\mathrm{x})$ and the shear stress $\tau^{1,2}(\mathrm{x})$ between the cement concrete layer 2 and the bituminous layer 1. Depending on the ratio of modulus of the two material layers and the loading value, the distribution of the normal stress at the interface may become negative around the corresponding bending force locations of points B and C. The use of an anti-symmetrical specimen increases the chances to get cracks (such as a debonding) around point $\mathrm{A}$ before point $\mathrm{D}$. But, depending on the mechanical resistance of the interface material and the material of layer 2, debonding may occur between the layers or not as it will be presented in the following sections for the UTW type of interface.

In addition, to study crack initiation problems with help of the M4-5n, two delamination criteria in the angle-ply laminates have been proposed (Chabot, 1997, 2000) (Caron et al., 2006). The first one is based on the maximum value of interface stresses. Using the virtual crack closure technique (VCCT) (Bui, 1978) (Moutou Pitti et al., 2008), the second criterion is based on an analytical calculation of the individual strain energy release rates $\left(\mathrm{G}_{\mathrm{I}}, \mathrm{G}_{\mathrm{II}}, \mathrm{G}_{\mathrm{III}}\right)$. At a given crack length, the VCCT yields an expression involving interfacial forces and relative displacements near the crack tip. For the 4PB test with a debonding crack length "a", the analytical expression of strain energy release rates is given in (Eq. 1). Only $G_{I}$ is a pure quadratic function of the 
normal interface stress. $\mathrm{G}_{\mathrm{II}}$ takes into account the combined terms containing the shear interface stress, and the generalized out-of-plane shear stress resultants $Q_{1}^{i}$ of each layer i.

$$
\begin{aligned}
& G_{T}(a)=G_{I}(a)+G_{I I}(a) \\
& \text { with }\left\{\begin{aligned}
G_{I}(a)= & \frac{1}{2 b} \cdot \frac{13\left(e^{1} E^{2}+e^{2} E^{1}\right)}{35 E^{1} E^{2}}\left(v^{1,2}(a)\right)^{2} \\
G_{I I}(a) & =\frac{1}{2 b} \cdot \frac{4\left(e^{1}\left(1+v^{1}\right) E^{2}+e^{2}\left(1+v^{2}\right) E^{1}\right)}{15 E^{1} E^{2}}\left(\tau^{1,2}(a)\right)^{2} \\
& -\frac{1}{2 b} \cdot\left(\frac{\left(1+v^{1}\right)}{5 E^{1}} Q_{1}^{1}(a)+\frac{\left(1+v^{2}\right)}{5 E^{2}} Q_{1}^{2}(a)\right) \cdot \tau^{1,2}(a)
\end{aligned}\right.
\end{aligned}
$$

As explained and illustrated in details in (Chabot et al., 2013a, 2013b), according to the principles of linear elastic fracture mechanics, from the sign of the derivative of energy release with respect to the crack length, the crack is expected to propagate initially along the interface in a unstable way before this propagation becomes stable from a given crack length value (function of the values of the materials and the geometry of the specimen). The instable part of this propagation has been specifically illustrated very recently on two specimens only, by means of a high-speed digital photography (Mulian \& Rabinovitch, 2016).

Before testing the bi-layer specimen made of pavement materials, a benchmark procedure has been used on homogeneous materials (Aluminium and PVC) chosen for their equivalent ratio of Young modulus to those studied in the case of Ultra-Thin White-topping pavement (UTW) made of a cement concrete overlay on bituminous material at ambient temperature. The reference specimen, made with an aluminium (Alu) homogeneous layer 2 sticks with epoxy glue on PVC homogeneous layer 1, has been tested $(\mathrm{L}=420 \mathrm{~mm} ; \mathrm{b}=125 \mathrm{~mm} ; \mathrm{a} 1=40 ; \mathrm{a} 2=71 ; \mathrm{e} 1=30.6 ; \mathrm{e} 2=40.6 \mathrm{~mm}$; Young modulus ratio: $\left.\mathrm{E} 2 / \mathrm{E} 1 \approx 22.4 ; \quad v^{1}=0.30 ; v^{2}=0.34\right)$. The benchmark procedure has confirmed successfully the simulation results of this brittle fracture mechanics approach. As expected, the debonding phenomenon is coming very rapidly from the expected edge until the half-length of the specimen (between the two static loading forces) (Figure 4) (Hun, 2012).

Using the Digital Image Correlation (DIC) method (see the details given in $\S 4$ ), the crack length "a" at the interface is estimated. For each crack length, the crack opening $\delta_{z}$ and sliding $\delta_{x}$ displacements are measured (Figure 1). Analytical expressions (Eq. 2) from the literature provides in 2D the corresponding elastic energy release rate $\mathrm{G}$ of each mode I and II (Hutchinson et al., 1987), where $\alpha$ and $\beta$ are the Dunder's nondimensional constants of a bi-material structure (Dunders, 1969). 


$$
G=\frac{\left(K_{1}^{2}+K_{2}^{2}\right)}{E^{*} \cosh ^{2}(\pi \varepsilon)} \quad \text { with }\left\{\begin{array}{l}
\frac{2}{E^{*}}=\frac{\left(1-v_{1}^{2}\right)}{E_{1}}+\frac{\left(1-v_{2}^{2}\right)}{E_{2}} \\
\varepsilon=\frac{1}{2 \pi} \ln \left[\frac{1-\beta}{1+\beta}\right] \\
\beta=\frac{E_{2}\left(1-2 v_{1}\right)\left(1+v_{1}\right)-E_{1}\left(1-2 v_{2}\right)\left(1+v_{2}\right)}{2\left[E_{1}\left(1-v_{2}^{2}\right)+E_{2}\left(1-v_{1}^{2}\right)\right]}
\end{array}\right.
$$

Accordantly to the M4-5n calculations, 2D plane strain assumptions are chosen. In (Eq. 2), each intensity factor $\mathrm{K} 1$ and $\mathrm{K} 2$, at a distance " $\mathrm{r}$ " from the crack tip, is calculated according to the expressions below (Eq. 3).

$$
\left\{\begin{array}{l}
K_{1}=\frac{E^{*} \cosh (\pi \varepsilon)}{8} \sqrt{\frac{2 \pi}{r}}\left[\left(\delta_{z}-2 \varepsilon \delta_{x}\right) \cos (\varepsilon \ln r)+\left(\delta_{x}+2 \varepsilon \delta_{z}\right) \sin (\varepsilon \ln r)\right] \\
K_{2}=\frac{E^{*} \cosh (\pi \varepsilon)}{8} \sqrt{\frac{2 \pi}{r}}\left[\left(\delta_{x}+2 \varepsilon \delta_{z}\right) \cos (\varepsilon \ln r)-\left(\delta_{z}-2 \varepsilon \delta_{x}\right) \sin (\varepsilon \ln r)\right]
\end{array}\right.
$$

The results of the M4-5n strain energy release rate (Eq. 1) are then compared to these classical formulae from the literature. Table 1 shows that the energy release rates of the M4-5n calculus for a given crack length "a" are validated compared to Dundurs's approach (Hun, 2012) (Chabot et al., 2016a). Modelling the epoxy glue (of a negligible thickness in comparison of layer 1 and 2 ones) as a contact surface in the M4-5n modelling seems in that case a reasonable assumption. In such a conditions, Mode I is recognized as the main failure mode.

\section{Bi-Layer Specimen Characteristics and Preparation}

The specimens are made in the laboratory under the same conditions and with the same constituents.

\subsection{Materials Characteristics}

The bituminous material tested in this study, is a classical French bituminous mix (NF EN 13108-1). It is obtained by using aggregate size $0 / 10$ and $5 \%$ of pure bitumen with $35 / 50$ penetration grade. Compaction is carried out with a linear compactor. The compaction procedure followed (tire pressure and number of passages) is the same for all samples. .As for another study dealing with quantifying expansion effects induced by freeze-thaw cycles in such a material (Mauduit et al., 2010, 2012), on the contrary to the normal void content value of $6 \%$ for such a material, this material features a high air void content.. The gamma ray bench is used to check the homogeneity of a sample in volume. An investigation with gamma bench shows that the average porosity of the asphalt mixes near the surface is about $9.6 \%$ before the application of the concrete layer. Due to introduction of the concrete material in the porosity of bituminous material, the voids content to $7.5 \%$. For the test condition at a displacement-controlled of a $0.7 \mathrm{~mm} / \mathrm{min}$ loading rate, the equivalent elastic modulus value of the bituminous material equals approximately $2000 \mathrm{MPa}$ at $20^{\circ} \mathrm{C}$ (Hun, 2012). The Poisson's ratio 
parameter is chosen to be an elastic constant scalar and equal to 0.35 .

The cement concrete material, denoted BC6, is made with a CEM I 52.5R cement (NF EN 206-1). Its water/cement ratio is equal to 0.68. The aggregate size of the cement concrete material is $0 / 11$ and it has a void content of $2.6 \%$. The Young measured modulus has an average value around $35000 \mathrm{MPa}$ and the Poisson's ratio is classically equal to 0.25 . Moreover, Rt $(=3.46 \mathrm{MPa})$ and $\mathrm{Rc}(=47.67 \mathrm{MPa})$ classically denote the tensile and compressive strength values, respectively of the material.

According to the conventional UTW technics, the cement concrete layer is casted directly onto the previous prefabricated bituminous (only water-cleaned before). Then after one month, the composite slabs are sawed into three specimens (denoted IPT-Nºslab- $\mathrm{N}^{\circ}$ specimen).

\subsection{Specimen Preparation for Testing Under Water Conditions}

In order to evaluate the additional effect of water during the debonding process, an aquarium is built. Prior being tested, each specimen is vacuum saturated by water with a depression of $86 \mathrm{kPa}$ as proposed in the European standard NF EN 12697-12. It consists in saturated the specimen in an air void box filled of water during two hours (Figure 5a and Figure 5b). Then each specimen waiting for being tested is conserved in a container filled of water (Figure 5c). According to the percentage of void content of each material, Table 2 resumes coarsely the parameters of the saturated specimens tested in water.

\section{Experimental Result Analysis}

The experiment results given in this paper are part of two chronological campaign studies made under controlled displacement conditions $(0.7 \mathrm{~mm} / \mathrm{mn})$ at around $20^{\circ} \mathrm{C}$ (Hun, 2012). Differences between specimens tested in air and ones tested in the water bath are emphasized in the aim to confirm or not if water has an effect in the debonding phenomenon. In that paragraph, only the bi-layer specimens that lead to a final debonding are studied. Two different width values ( $b=100$ or $120 \mathrm{~mm})$ of the specimen are considered, as well as symmetrical $\left(\mathrm{a}_{2}=70 \mathrm{~mm}\right)$ and non-symmetrical $\left(\mathrm{a}_{2}=40 \mathrm{~mm}\right)$ dimension.

Tests are performed on a mechanical press. During the test, the specimen temperature is controlled in the climatic aquarium chamber (Figure 6a) (Hun, 2012). The wall glass of the aquarium, with its refraction index identical to the water one, allows using the DIC system. So the main advantage of this chamber is to offer the possibility to follow with a visual or digital image inspection, every side and the fracture zone of the specimen during the test and to submerge the specimens tested under water conditions. To control and measure the imposed displacement, a linear variable differential transducer (LVDT) sensor is placed mid-height on the specimen section at the mid-span (Figure 6a). In addition the loading force value is displayed directly on the test equipment, in the aim to follow by this means its value directly on the captured images (Figure 6.b). 
The detailed test temperatures, dimension and fracture observations for each specimen are summarized in the table 3 for bi-layer specimens tested in air, and table 4 for bi-layer specimens tested into the water bath. First, the final failure observations are given. Then, the force-displacement curves are presented before being discussed.

\subsection{Final Failure Observations in the Bi-Layer Specimens Tested}

Among the eight UTW specimens tested in air, four specimens (Number: 1-1, 1-3, 3-1 and 5-1) have failed with an interface-debonding mode between layers (Hun, 2012) (Chabot et al., 2013a). The three bi-layer specimens tested in the water bath (Number: 4-3, 6-2 and 6-3) all failed by debonding mode. Table 3 and Table 4 give some details about the geometry and the visual observations of failures that occurred in each specimen. Figures 7 and 8 illustrate that delamination occur exactly at the interface location between layers for both test conditions. This finding implies that even if cement concrete fills the bituminous material voids and assumed to strengthen so the interface in the bituminous material just under the interface, the present four-point bending test is still able to delaminate the bi-layer. This test produces an adhesive fracture for this type of interface between the layer made of a cement concrete material that has been flowing on top of the layer made of the bituminous material, as is conventionally anticipated for a UTW structure. The final average debonding length of bi-layer specimen gives $59 \mathrm{~mm}$ for specimens tested in air compared to $97 \mathrm{~mm}$ for specimens tested into water. As observed and measured, the fracture interface area of specimens tested into water are more than $30 \%$ bigger $\left(\mathrm{S}_{\text {Raverage }} \approx 9716 \mathrm{~mm}^{2}\right)$ than those tested in air $\left(\mathrm{S}_{\text {Raverage }} \approx 6512 \mathrm{~mm}^{2}\right.$ ) (see Table 3 and 4). The surface of debonding is larger for bi-layer specimens that have being conserved more time in a container filled of water before being tested (see Table 2). The 1PT-4-3 specimen has a final fracture zone similar to the one observed for the Alu/PVC one specimen (Figure 4b).

\subsection{Force-Displacement Results and Discussion}

For each type of moisture condition, the different test results are displayed in the same Force-Displacement graphs (Figures 9 and 10). In these curves, the load $\mathrm{F}$ is multiplied by a coefficient denoted $\mathrm{C}_{\mathrm{F}}\left(\mathrm{C}_{\mathrm{F}}=\mathrm{S} / \mathrm{Sspec}\right)$. That coefficient depends on the ratio of the interface area of the anti-symmetrical specimen $(S=(L-a 1-a 2) * b$, with $a 1=70 \mathrm{~mm}$, $\mathrm{a} 2=40 \mathrm{~mm}$ and $\mathrm{b}=100 \mathrm{~mm}$ ) and the value of the interface area of the specimen tested $\left(\mathrm{Sspec}=(\mathrm{L}-\mathrm{a} 1-\mathrm{a} 2 \mathrm{spec})^{*}\right.$ bspec with a2spec $=40$ or $70 \mathrm{~mm}$ and $\mathrm{bspec}=100$ or $\left.120 \mathrm{~mm}\right)$. For the anti-symmetrical specimen, the $C_{F}$ coefficient is equal to 1 . It is the case for all the specimens tested into the water bath (Figure 9) and the specimen 1-PT-5-1 tested in the air. On the Figure 10, S/Sspec is equal to 1.11 for specimen 1-PT-1-3 and S/Sspec is equal to 0,92 for specimen 1-PT-1-1 and 1-PT-3-1. The S/Spec coefficient offers the advantage to display all the experimental results (from different test campaigns) on the same curve system in term of interface-normalized area between layers. It does not affect too much the global shape of one curve in comparison to another one. Of course, this coefficient is not used at all in any further calculation. 
On the contrary to those tested in the air (Figure 10), one can observed, that the load value of specimens tested in the water bath, decreases suddenly after its maximum value (Figure 9).

M4-5n calculations indicate that, at a loading force of $\mathrm{F}=4.2 \mathrm{kN}$, the tensile stress (Rt) at the bottom of the layer 2 made of the cement concrete tested air is supposed to reach its maxi-mum tensile value (around $\mathrm{Rt}=3.46 \mathrm{MPa}$ ) at point $\mathrm{B}$ before point $\mathrm{C}$ in the case of an anti-symmetrical specimen geometry $(L=480 \mathrm{~mm} ; b=100 \mathrm{~mm} ; \mathrm{a} 1=70 ; a 2=40$; $\mathrm{e} 1=\mathrm{e} 2=60 \mathrm{~mm} ; \mathrm{E} 2 / \mathrm{E} 1 \approx 17.5 ; v^{1}=v^{2}=0.35$ ) (Figure $3 \mathrm{a}$ ).

In Table 3 and 4, the " $d$ " value is the length of the supposed damaged zone of the bi-layer beam contained between the maximum of the tension stress admitted for the cement concrete material (around $4200 \mathrm{~N}$ for a bi-layer beam with $b=100 \mathrm{~mm}$ and $\mathrm{a}_{2}=40 \mathrm{~mm}$ or $70 \mathrm{~mm}$, around $5000 \mathrm{~N}$ for a bi-layer beam with $\mathrm{b}=120 \mathrm{~mm}$ and $\mathrm{a}_{2}=70 \mathrm{~mm}$ ) and the maximum loading force of the bi-layered beam. The results show that the average value of this length zone " $\mathrm{d}$ " is approximately $18,8 \%$ much more larger for specimens tested in air $\left(\mathrm{d}_{\text {average }}=154.4 \mathrm{~mm}\right)$ that those tested into a water bath $\left(\mathrm{d}_{\text {average }}=\right.$ $125.3 \mathrm{~mm}$ ). Into water, its damage zone reduced, the debonding resistance of such a specimens seems better but much more brittle than in air. In that case, the maximum of the tension stress of the cement concrete material tested into the water bath seems higher. This phenomenon has also being seen for $4 \mathrm{pt}$ bending tests made, into a water bath, on mono layer specimens of cement concrete material. On these mono layer specimens made with the cement concrete material only, it has been observed on the " $\mathrm{d}$ " values that water bath effect reduces around 1/3 the damage zone of the cement concrete (Hun, 2012). These few results lead to the assumption that, in the case of the bi-layer specimens tested in the air, the bituminous material seems to control in its bond the different failures of the cement concrete material.

So, as opposed to tests conducted on Alu/PVC specimens, the competition between the poor tensile resistance of the cement concrete layer and the good bond of such an interface, made of cement concrete casted on the bituminous material, adds complexity to the analysis. Then the determination of strain energy release rate is more complicated for this type of bi-layer specimen. However for specimens tested into water only, a first approximation can be tried with the help of DIC technics as explained in the following section.

\section{Digital Image Correlation (DIC) Analysis}

Practically, it is difficult to localize the initiation of delamination phenomenon onto the force-displacement curve. To do so, the Digital Image Correlation (DIC) measurement (Sutton et al., 1983) is used. During the mechanical test, the whole Lagrangian strain measurement is investigated by DIC technics in the aim to detect failure mechanisms of the bi-layer specimens. As previously exposed, the bending crack at the bottom of the concrete layer as well as the delamination phenomenon at the interface is expected. In this way, a full-range of displacement distribution is recorded at the interface between points A and B (Figure 1). 
In the DIC setup, an AVT PIKE F-145C camera is used. This camera combines good resolution for frame rate performance. The highest resolution of the camera is $1388 \times 1038$ pixels at 63 frames per second. The studied area on the specimen is chosen centralized on the interface from point A to point B (and a little after) (Figures 4a\&6b). The resolution of measurement window is: $680 \times 295$ pixels, which correspond to $115 \times 50 \mathrm{~mm} 2$. In another word, one pixel corresponds to $0.169 \mathrm{~mm}$ on sample surface. The unit subset of $32 \times 32$ pixels is chosen for the correlation calculation. During the measurement process, an image of the selected area is taken before and after the deformation. Then the DIC system applies the correlation algorithm for quantitatively evaluating the data of displacement and strain. The DIC system includes a camera with lens Nikkor AF $75 \mathrm{~mm} / \mathrm{F} 1.8$ Micro. It is placed in front of the specimen. The distance between the camera and the specimen is adjusted depending on the specimen area to be measured. The camera is connected to a computer in which the data is acquired and evaluated using the CORRELA software (Dupré et al., 2012). In order to eliminate interruptions from surrounding light, a LED white powerful light source is employed to illuminate the sample. To find the correspondence between each image and the loading conditions during the test, the resulting force and the displacement at the mid-span values are displayed directly in the specimen by using a video-projector (Figure 6b).

Only the specimen IPT-5-1, tested in the air, and the three specimens $\mathrm{N}^{\circ} 4-1,6$ 2 and 6-3, tested into the water bath, have been investigated by DIC Analysis. A first DIC observation confirms that, even if the IPT-5-1 specimen failed by debonding the interface, a vertical crack in the cement concrete material influences the delamination process (see the arrow on Figure 10 showing a vertical crack in a small red zone of the additional DIC window of the Figure 10). On the contrary, effect of vertical cracks has not been observed on 1PT-6-2 and 1PT-6-3 specimens tested in the water bath (see the DIC window on the Figure 9) (Hun, 2012). Figure 11 for the IPT-5-1 specimen and Figure 12, 13 and 14, for the three specimens $\mathrm{N}^{\circ} 4-1,6-2$ and 6-3 respectively tested in the water bath, illustrate in more details displacement measurements obtained by DIC method. The measurement of the lateral displacement Ux is done between point $\mathrm{A}$ and after point $\mathrm{B}$ at the bottom of the cement layer (Figure 1). Without any vertical cracks in the cement layer, the Ux should be almost equal to zero (less than $1.69 \mu \mathrm{m}$ ). Differences of bending displacement $\Delta \mathrm{Uy}$, obtained just above and just under of the interface, are calculated also between these two points. One consider then that debonding occurs when this difference is different to zero. In each of these curves, "I" and "II" denote, per each picture number and load value, the location before and after the maximum load value respectively ("No picture I or II - Load value (N)"). First, in all the DIC results, Figures 11-14 illustrate that when the delamination phenomenon happens, the loading values have already decreased.

In dry condition, Figure $11 \mathrm{~b}$ confirms that when the debonding first is observed by DIC on the $\Delta \mathrm{Uy}$ measured at the point $\mathrm{N}^{\circ} 2050$, a vertical crack at the bottom of the cement concrete layer already exists at the point $\mathrm{N}^{\circ} 867$ (Figure 11a).

In wet conditions, for the 1-PT-4-3 specimen that was kept for a long time in the water bath before being tested (Table 2), the Ux result of Figure 12a illustrates that no vertical crack is observed on the DIC window but that delamination propagation occurs 
very rapidly between points $\mathrm{N}^{\circ} 1748$ and $\mathrm{N}^{\circ} 1749$ (Figure $12 \mathrm{~b}$ ). For the 1-PT-6-2 and 1PT-6-3 specimens it is observed that when a vertical crack is coming from the bottom of the cement concrete layer automatically a debonding phenomenon appears between the two layers relaxing the vertical crack opening (Point $\mathrm{N}^{\circ} 715$ for the specimen 1-PT-6-2 Figure 13 and Point $\mathrm{N}^{\circ} 935$ for the specimen 1-PT-6-3 - Figure 14). The energy of this vertical crack is assumed not being the main part of the process during the debonding and before the end of the test. Then a tentative calculation of fracture energy $G_{F}$ of a corresponding increment in crack length between two points A and B seems possible. This direct evaluation of the fracture energy part in mode $I$ is calculated from the experimental Force-Displacement curve according to the area method (Davidson \& Lee, 1995) and as follow (Eq. 4).

$G_{1 C}=\frac{F_{A} \delta_{B}-F_{B} \delta_{A}}{2 b\left(a_{2}-a_{1}\right)}$

Such an area method is assumed to quantify the propagation toughness. The calculation is done assuming that DIC measurement provides the crack length of each test (between pictures $\mathrm{N}^{\circ} 715$ and $\mathrm{N}^{\circ} 800$ for the specimen 1-PT-6-2 and between the point $\mathrm{N}^{\circ} 935$ and the point $\mathrm{N}^{\circ} 1000$ for the specimen 1-PT-6-3) (Figure 9). The corresponding facture energy are given in $\mathrm{Eq}(5)$ and $\mathrm{Eq}(6)$.

$G_{F_{6-2}}=\frac{F_{N^{\circ} 715} \delta_{N^{\circ} 800}-F_{N^{\circ} 800} \delta_{N^{\circ} 715}}{2 b\left(a_{N^{\circ} 800}-a_{N^{\circ} 715}\right)}$

$G_{F_{6-3}}=\frac{F_{N^{\circ} 935} \delta_{N^{\circ} 1000}-F_{N^{\circ} 1000} \delta_{N^{\circ} 935}}{2 b\left(a_{N^{\circ} 1000}-a_{N^{\circ} 935}\right)}$

This calculation gives around $142 \mathrm{~J} / \mathrm{m} 2$ and $112 \mathrm{~J} / \mathrm{m} 2$ for specimens I-PT-6-2 and I-PT-63 respectively. That is to say the average fracture energy for debonding specimens tested in the water bath, in mixed mode condition (mainly mode I), is around $127 \mathrm{~J} / \mathrm{m} 2$ instead of $166 \mathrm{~J} / \mathrm{m} 2$ according to the first results coming from the macro elastic modelling approach (Table 1). All of these $\mathrm{G}_{\mathrm{F}}$ results are in order of those coming from the literature under Mode I opening condition and the same type of bi-layers (Tchegg et al., 2007) (Gharbi et al., 2017).

\section{Conclusion/perspectives}

In order to investigate the mechanical behaviour of interface between pavement layers under water, a 4PB test has been adapted here. Using the VCCT theory and a debonding assumption, individual strain energy release rates are calculated with a specific model, the M4-5n. These energy release rates of the M4-5n have been validated successfully compared to Dundurs's approach on a bi-layer specimen of homogenous materials (Alu/PVC). In such a mixed mode test the debonding mode I should be recognized as the main failure mode. The M4-5n analysis shows also that this test lead firstly to instable crack propagation (Chabot et al, 2013b). That is confirmed in that study.

On specimens made with a cement concrete overlay on a bituminous material layer (UTW specimen type), four test results and a DIC analysis confirm that, in dry conditions, the delamination process is in competition with micro cracks at the bottom 
of the cement concrete layer during the test. The adapted 4PT bending test may not be considered as a dedicated test for studying only the delamination process for this type of bi-layer specimen tested under dry conditions. On the contrary, all the three preliminary tests lead to confirm that water condition favours the study of debonding phenomenon in such a test. Due to the perfect elastic assumption in the model used here, first $G$ Dunders and M4-5n results given in Table 5 may be considered as maximum values for the tests obtained in the water bath. The DIC measurement is then used to deep the knowledge of this calculus.

Of course more tests are needed to confirm all these assumption, but these few experimental observations obtained here and the analysis of data by our macro modelling approach gives an idea on the different phenomena existing during the delamination process. The few fracture energy values obtained for bi-layer UTW specimen are in the range of ones obtained by pure Mode I test (Tchegg et al., 2007) (Gharbi et al., 2017). Compared with other different teams involved in the Rilem TC241-MCD with other couple of materials (Chabot et al., 2016b), all of this research work aims to deep the knowledge of debonding mechanisms in pavements.

\section{Acknowledgements:}

The authors are grateful to Sofiane Guessasma, Octavian Pop, Marc François and Guillaume Le Gallec for their help of using DIC analysis.

\section{References:}

Barman, M., Vandenbossche, J., Mu, F., Gatti, K. (2011). Development of design guide for thin and ultra-thin concrete overlays of existing asphalt pavements, task 1 report : Compilation and review of existing performance data and information. Technical report, FHWA Pooled Fund Study TPF 5-65, Retrieved from https://www.engineering.pitt.edu/uploadedFiles/_Content/Sub_Sites/Faculty_Su bsites/Vandenbossche/Documents/TPF\%205165\%20Task\%201\%20Final\%20Report.pdf.

Bui, H. (1978). Mécanique de la rupture fragile. Paris : Ed Masson.

Caron, J. F., Diaz Diaz, A., Carreira, R.P., Chabot, A., Ehrlacher, A. (2006). Multiparticle modeling for the prediction of delamination in multi-layered materials. Composites Science and Technology, 66(6), 755-765. doi: 10.1016/j.compscitech.2004.12.022

Chabot, A. (1997). Analyse des efforts à l'interface entre les couches des matériaux composites à l'aide de Modélisations Multiparticulaires des Matériaux Multicouches (M4). ENPC PhD thesis, Paris. Retrieved from https://tel.archivesouvertes.fr/tel-00197853

Chabot, A., \& Ehrlacher, A. (1998). Modèles Multiparticulaires des Matériaux Multicouches M4_5n et M4_(2n+1)M pour l'étude des effets de bord. Proceedings of the Comptes-rendus aux 11ème Journées Nationales sur les Composites (JNC11), 3, 1389-1397, Nov. 18-20, Arcachon, France. Retrieved from https://hal.archives-ouvertes.fr/hal-00325238/file/JNC11.pdf 
Chabot A., Cantournet S., A. Ehrlacher (2000). Analyse de taux de restitution d'énergie par un modèle simplifié pour un quadricouche en traction fissuré à l'interface entre 2 couches. JNC12, ENS de Cachan, ISBN 2-9515965-0-2, 2 : 775-784.

Chabot, A., Tran, Q. D., \& Pouteau, B. (2004). Simplified modelling of a cracked composite pavement. Poster presented at the first International Elsevier Conference on Failure Analysis, July 12-14, Lisbonne, Portugal.

Chabot, A., Tran, Q. D., \& Ehrlacher, A. (2005). A simplified modeling for cracked pavements. Bulletin des Laboratoires des Ponts et chaussées, (258-259), 105120. ISSN 1269-1496.

Chabot, A., Tran, Q. D., \& Ehrlacher, A. (2007). A modeling to understand where a vertical crack can propagate in pavements. Proceedings of the International Conference on Advanced Characterization of Pavement and Soil Engineering Materials, June 20- 22, Athens, Greece. In Taylor \& Francis Group Proceedings, 1, 431-440. Print ISBN 978-0-415-44882-6.

Chabot, A., Pouteau, B., Balay, J.-M., De Larrard, F. (2008). FABAC Accelerated Loading Test of Bond between Cement Overlay and Asphalt layers. Proceedings of the Sixth International RILEM Conference on Cracking in Pavements, June 16-18, Chicago, US. In Taylor \& Francis Group Proceedings, 13-23. Print ISBN 978-0-415-47575-4.

Chabot, A., Hun, M., \& Hammoum, F. (2013a). Mechanical analysis of a mixed mode debonding test for "composite" pavements. Construction and Building Materials, 40, 1076-1087. doi: 10.1016/j.conbuildmat.2012.11.027

Chabot A., Hun M., Hammoum F. (2013b). Determination of energy release rate for a mixed-mode debonding test for « composite » pavements. 6th International Symposium on defect and Material Mechanics, 31-32, July 1-5, ECN, France.

Chabot, A., Hammoum, F., \& Hun, M. (2016a). Mixed - Mixed-mode debonding approach to evaluate water sensibility in bi-layer composite pavements. 8th International conference on Mechanisms of Cracking and Debonding in Pavements (MCD2016), June 7-9, Nantes, France. Springer RILEM Bookseries, 13, 613-618, ISBN: 978-94-024-0867-6. doi: 10.1007/978-94-024-0867-6_86

Chabot A., Buttlar B., Dave E., Petit C., Tebaldi G. (Eds), 1st ed. (2016b). Cracking and Debonding in Pavements" - 8th RILEM International Conference on Mechanisms of Cracking and Debonding in Pavements Springer Series: RILEM Bookseries, Vol. 13, ISBN 978-94-024-0866-9, DOI: 10.1007/978-94-0240867-6.

Davidson R., \& Lee R.J. (1995). Experimental Methodologies to determine the fracture properties of adhesive joints. MTS Adhesives Project 2: Failure Modes and Criteria Report $N^{\circ} 2, \quad$ Retrieve from http://www.adhesivestoolkit.com/PDFFiles/Project\%202/P2r2.pdf

De Larrard, F., Chabot, A., Sedran, T., Pouteau, B., Mathias, V. (2005). Recent developments in French concrete pavement technology. Global Construction: Ultimate concrete opportunities, Dundee, Scotland, 5-7 July 2005. Proceedings of the International Conference on concrete for transportation Infrastructure, 1926. Print ISBN: 978-0-7277-3402-0. doi: 10.1680/cfti.34020 
Dundurs, J. (1969). Edge-bonded dissimilar orthogonal elastic wedges under normal and shear loading. Transactions of the ASME, Journal of Applied Mechanics, 650-652. doi:10.1115/1.3564739

Dupré, J. C., Doumalin, P., Valle, V., Brémand, F. (2012). Mode d'emploi du logiciel correla V2012. Notice d'utilisation du logiciel.

Gharbi, M., Nguyen, M.L., \& Chabot, A. (2017). Experimental evaluation of the interface fracture energy for composite pavements. In the Proceedings of the $7^{\text {th }}$ International EATA Conference, June 12 - 14, Zürich, Switzerland.

Hutchinson J.W., Mear M. E., \& Rice J. R. (1987). Crack Paralleling interface between Dissimilar Materials. Journal of Applied Mechanics, 109, 828-832.

Hun, M. (2012). Influence de l'eau sur le décollement d'une interface par flexion d'un bicouche de chaussée urbaine. ECN $\mathrm{PhD}$ thesis, France. Retrieved from https://tel.archives-ouvertes.fr/tel-00851093

Hun, M., Chabot, A., \& Hammoum, F. (2012). A four point bending test for the bonding evaluation of composite pavement. 7th Rilem International Conference on Cracking in Pavements, 20-22 June, Delft, The Netherlands. Springer RILEM Bookseries, 4, 51-60. doi: 10.1007/978-94-007-4566-7_6

Mateos, A., Harvey, J., Paniagua, J., Paniagua, F., Fan, A., 2016. Role of ConcreteAsphalt Interface in bonded Concrete Overlays of asphalt Pavements. 8th International conference on Mechanisms of Cracking and Debonding in Pavements (MCD2016), Nantes, France, June 7-9. Springer RILEM Bookseries, 13, 613-618, ISBN: 978-94-024-0867-6. doi: 10.1007/978-94-024-0867-6_68

Mauduit, C., Hammoum, F., Piau, J.M., Mauduit, V., Ludwig S., Hamon D. (2010). Quantifying expansion effects induced by Freeze-Thaw cycles in partially water saturated bituminous mix: Laboratory Experiments. Road Materials and Pavement Design, 11 (Supplement 1): 443-457. doi: 10.1080/14680629.2010.9690341

Mauduit V., Mauduit C., Vulcano-Grellet N., Coulon N., Hammoum F., Hamon D., Kerzreho JP, Piau JM, Chabot A. (2013). Dégradation subite des enrobés bitumineux par période de gel/dégel : analyse de cas de terrain et recherche exploratoire en laboratoire. Bulletin des Laboratoires des Ponts et chaussées. ISSN 1269-1496, (279), 47-63.

Moutou Pitti, R., Dubois, F., Petit, C., Sauvat, N ., Pop, O. (2008). A new M-integral parameter for mixed-mode crack growth in orthotropic viscoelastic material. Engineering Fracture Mechanics, 75(15), 4450-4465. doi: 10.1016/j.engfracmech.2008.04.021

Mulian G. \& Rabinovitch O. (2016). Experimental and analytical study of the dynamic debonding in FRP plated beams. International Journal of Solids and Structures, 92-93, 121-134. doi: 10.1016/j.ijsolstr.2016.03.020

Naciri, T., Ehrlacher, A., \& Chabot, A. (1998). Interlaminar Stress Analysis with a new Multiparticle Modelisation of Multilayered Materials (M4). Composites Sciences and Technology, 58 (3), 337-343. doi: 10.1016/S0266-3538(97)000857 
Nasser H., Piau J.M., Chupin O., Chabot A., 2016. M4-5n numerical solution using the Mixed FEM, validation against the Finite Difference Method. 8th International conference on Mechanisms of Cracking and Debonding in Pavements (MCD2016), Nantes, France, June 7-9, 2016. A. Chabot et al. (Eds). Springer RILEM Bookseries, 13: 363-369, ISBN: 978-94-024-0867-6. DOI: 10.1007/978-94-024-0867-6_51.

Pan, J., Leung, C. K. Y., \& Luo M. (2010). Effect of multiple secondary cracks on FRP debonding from the substrate of reinforced concrete beams. Construction and Building Materials, 24, 2507-2516. doi:10.1016/j.conbuildmat.2010.06.006

Perez, F., Bissonnette, B., \& Gagné, R (2009). Parameters affecting the debonding risk of bonded overlays used on reinforced concrete slab subjected to flexural loading. Materials and Structures, 42 (5), 645-662. doi: 10.1617/s11527-0089410-x

Pouteau, B., Balay, J. M., Chabot, A., De Larrard, F. (2004). Fatigue test and mechanical study of adhesion between concrete and asphalt. Proceedings of the 9th International Symposium on Concrete Roads, April 3-6, Istanbul, Turkey.

Raab, C., Partl, M. N., \& Abd El Halim, A. O. (2012). Effect of moisture on interlayer bonding of asphalt pavements. 7th Int. conf. on Maintenance and Rehabilitation of Pavements and Technological Control, August 28-3, Auckland, New Zealand.

Reissner E. (1950). On a variational theorem in elasticity, Math. Phys., 29: 90-95.

Roux, S., Rethore, J., \& Hild, F. (2009). Digital image correlation and fracture: an advanced technique for estimating stress intensity factors of $2 \mathrm{D}$ and $3 \mathrm{D}$ cracks. Journal of Physics D: Applied Physics, 42 (21), 214004. doi:10.1088/0022$3727 / 42 / 21 / 214004$

Sutton, M., Wolters,W., Peters,W., Ranson,W., McNeill, S. (1983). Determination of displacements using an improved digital correlation method. Image and Vision Computing, 1(3): 133-139. doi:10.1016/0262-8856(83)90064-1

Tschegg EK, Macht J, Jamek M, Stegenberger J., 2007. Mechanical and FractureMechanical Properties of Asphalt-Concrete Interfaces. ACI Materials, 104 (5): 474-480. doi:10.1016/0262-8856(83)90064-1

Teng, J., Smith, S., Yao, J., Chen, J. (2003). Intermediate crack-induced debonding in RC beams and slabs. Construction and Building Materials, 17 (6-7): 447-462.

Tran, Q. D., Chabot, A., Ehrlacher, A., Tamagny, P., (2004). A simplified modelling for cracking in pavements. Proceedings of the Fifth International RILEM Conference Cracking in Pavements, May 5-8, Limoges, France. In Rilem Proceedings PRO 37, 299-306, Print ISBN 2-912143-47-0.

Vulcano-Greullet, N., Kerzreho, J. P., Mauduit, V., Chabot, A. (2010). Stripping phenomenon of top layers of thick pavements. Proceedings of the 11th International Conference on Asphalt Pavements, August 1-6, Nagoya Aichi, Japan. Curran Associates, 1, 552-561. Print ISBN: 978-1-61839-073-8 


\section{List of Tables}

Table $1 \mathrm{M} 4-5 \mathrm{n}$ energy release rate results compared to Dunders ones for an Alu/PVC specimen (From (Chabot et al., 2016))

\begin{tabular}{lllll}
\hline & Crack length $(\mathrm{mm})$ & $\mathrm{G}_{\mathrm{I}}\left(\mathrm{J} / \mathrm{m}^{2}\right)$ & $\mathrm{G}_{\mathrm{II}}\left(\mathrm{J} / \mathrm{m}^{2}\right)$ & $\mathrm{G}_{\text {Total }}\left(\mathrm{J} / \mathrm{m}^{2}\right)$ \\
\hline Dundurs & $70 \pm 1$ & 93 & 35 & 128 \\
M4-5n & & 106 & 21 & 127
\end{tabular}

Table 2. Degree of water saturation of the specimen

\begin{tabular}{|c|c|c|c|c|c|}
\hline $\begin{array}{l}\text { Specimen } \\
\text { name }\end{array}$ & $\begin{array}{l}\text { Dry mass } \\
(\mathrm{g})\end{array}$ & $\begin{array}{l}\text { Wet mass } \\
(\mathrm{g})\end{array}$ & $\begin{array}{l}\text { Water volume } \\
\text { absorbed }\left(\mathrm{cm}^{3}\right)\end{array}$ & Saturated degree & $\begin{array}{l}\text { Submersion } \\
\text { time }\end{array}$ \\
\hline 1-PT-4-3 & 11554 & 11723 & 169 & 68.8 & 24 hours \\
\hline 1-PT-6-2 & 11536 & 11696 & 160 & 65.2 & 3 hours \\
\hline 1-PT-6-3 & 11384 & 11565 & 180 & 73.7 & 1 hour $1 / 2$ \\
\hline
\end{tabular}

Table 3. Details of the bi-layer specimens tested in air

\begin{tabular}{lllllrl}
\hline $\begin{array}{l}\text { Specimen } \\
\text { name }\end{array}$ & $\begin{array}{l}\mathrm{b} / \mathrm{a}_{2} \\
(\mathrm{~mm})\end{array}$ & $\begin{array}{l}\mathrm{F}_{\max } \\
(\mathrm{N})\end{array}$ & $\mathrm{d}(\mu \mathrm{m})$ & $\mathrm{T}^{\circ} \mathrm{C}$ & $\begin{array}{l}\mathrm{S}_{\mathrm{R}} \\
\left(\mathrm{mm}^{2}\right)\end{array}$ & Final Visual Observations \\
\hline 1-PT-1-1 & $120 / 70$ & 12150 & 144.7 & 21 & 6300 & Interface Debonding \\
1-PT-1-3 & $100 / 70$ & 9760 & 154.8 & 20 & 5550 & $\begin{array}{l}\text { Interface Debonding } \\
\text { 1-PT-3-1 }\end{array}$ \\
$120 / 70$ & 11560 & 182.9 & 20 & 9000 & $\begin{array}{l}\text { Cracking in cement concrete layer (point } \\
\text { B) then interface debonding }\end{array}$ \\
1-PT-5-1 & $100 / 40$ & 9770 & 143.6 & 20.5 & 5200 & $\begin{array}{l}\text { Cracking in cement concrete layer (point } \\
\text { B) then interface debonding }\end{array}$
\end{tabular}

Table 4. Details of the saturated bi-layer specimens tested in the water bath

\begin{tabular}{lllllll}
\hline $\begin{array}{l}\text { Specimen } \\
\text { name }\end{array}$ & $\begin{array}{l}\mathrm{b} / \mathrm{a}_{2} \\
(\mathrm{~mm})\end{array}$ & $\begin{array}{l}\mathrm{F}_{\max } \\
(\mathrm{N})\end{array}$ & $\mathrm{d}(\mu \mathrm{m})$ & $\mathrm{T}^{\circ} \mathrm{C}$ & $\begin{array}{l}\mathrm{S}_{\mathrm{R}} \\
\left(\mathrm{mm}^{2}\right)\end{array}$ & Final Visual Observations \\
\hline 1-PT-4-3 & $100 / 40$ & 9490 & 137.0 & 20 & 15500 & Interface Debonding \\
1-PT-6-2 & $100 / 40$ & 11310 & 135.5 & 19.7 & 7600 & Interface Debonding \\
1-PT-6-3 & $100 / 40$ & 11300 & 103.3 & 19.9 & 6050 & Interface Debonding
\end{tabular}

Table 5. Average M4-5n energy release rate results compared to Dunders ones for 1PT-6-2 \& 1PT-6-3 specimens tested into water

\begin{tabular}{|c|c|c|c|c|}
\hline & Crack length (mm) & $\mathrm{G}_{\mathrm{I}}\left(\mathrm{J} / \mathrm{m}^{2}\right)$ & $\mathrm{G}_{\mathrm{II}}\left(\mathrm{J} / \mathrm{m}^{2}\right)$ & $\mathrm{G}_{\text {Total }}\left(\mathrm{J} / \mathrm{m}^{2}\right)$ \\
\hline Dundurs & \multirow{2}{*}{16,5} & 157,5 & 22 & 179 \\
\hline M4-5n & & 155 & 18 & 173 \\
\hline
\end{tabular}




\section{List of Figures}

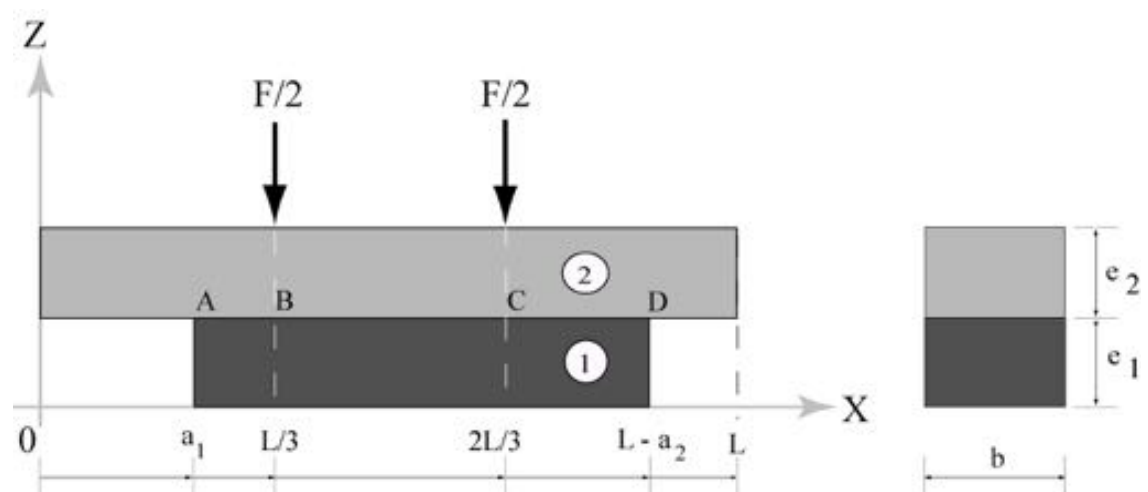

Figure 1. The geometric parameters of the anti-symmetric specimen used in the four Point bending test

(b)

(a)

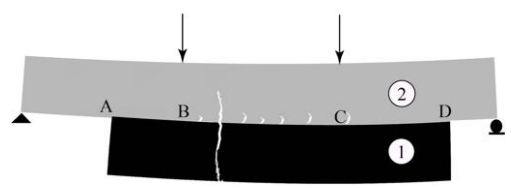

(c)

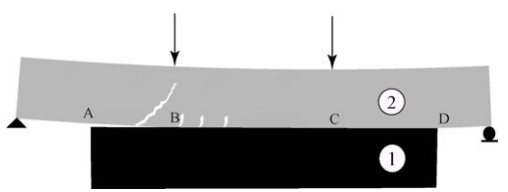

Figure 2. The different fracture configurations of the bi-layer specimens (a) Debonding configuration (b) UTW specimen case: Main crack at the bottom of the cement concrete layer between points A and B; (c) UTW specimen case: Interface debonded and combined with the cement concrete cracked

(a)

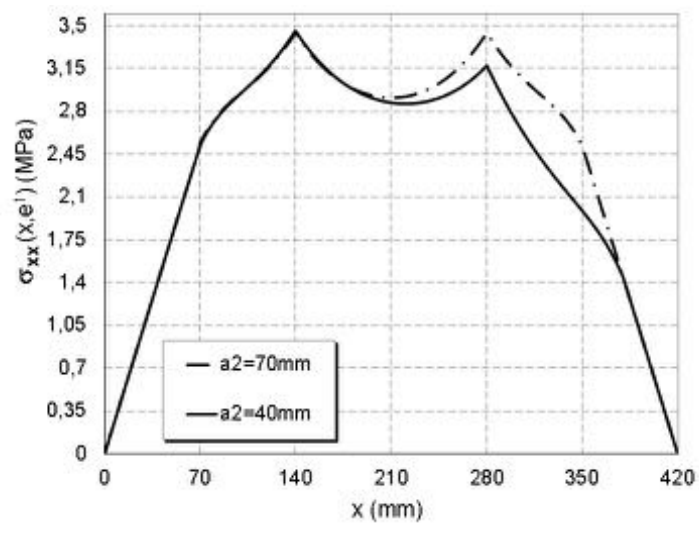

(b)

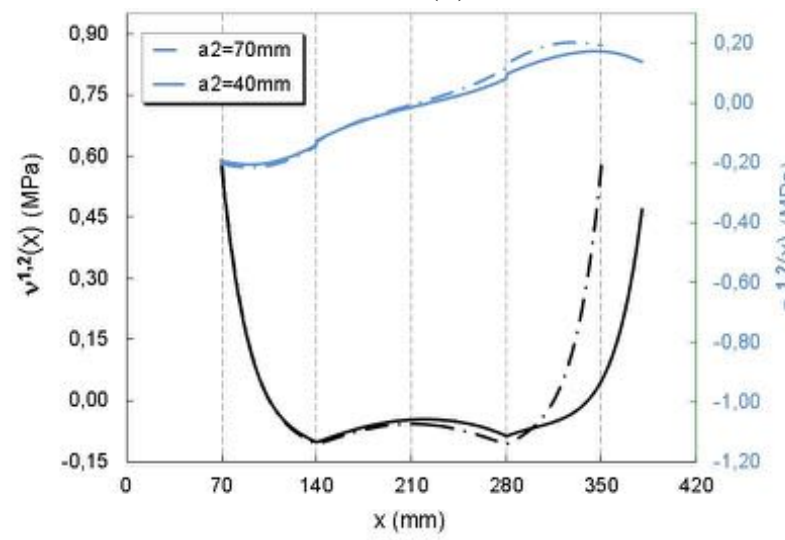

Figure 3: Comparison of the stress distributions between a symmetrical $(\mathrm{a} 2=70 \mathrm{~mm})$ and an antisymmetrical specimen $(\mathrm{a} 2=40 \mathrm{~mm})$ for $\mathrm{F}=4.2 \mathrm{~N}$ and $\mathrm{b}=100 \mathrm{~mm}$ : (a) tensile stress distribution at the bottom of the cement concrete layer; (b) distribution of the interface stresses of the M4-5n 


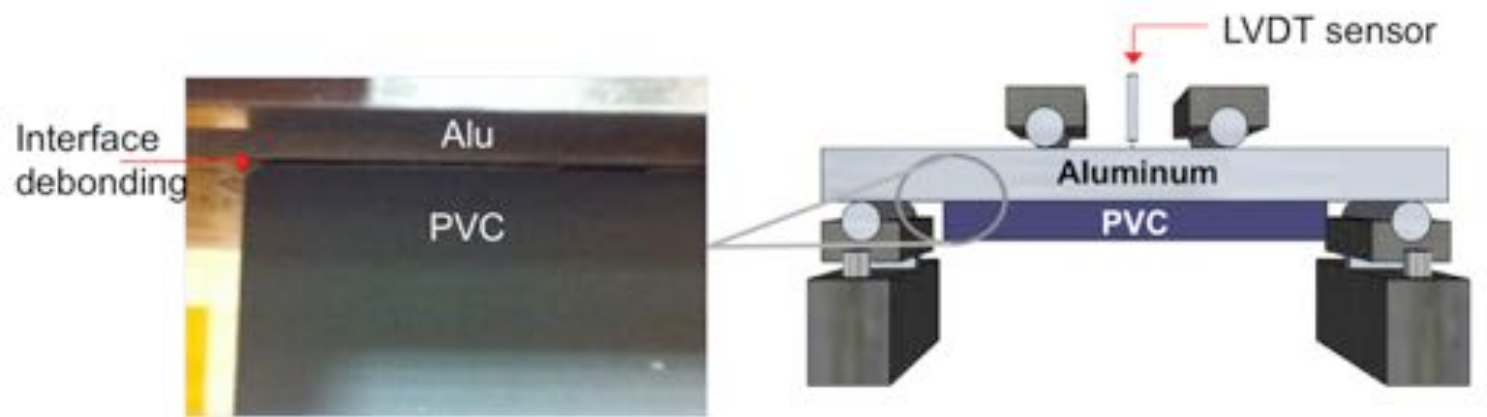

Figure 4. The four point bending test on an Alu/PVC specimen (From (Hun, 2012)): (a) The Interface debonding phenomenon observed; (b) General view of the Alu/PVC specimen

(a)

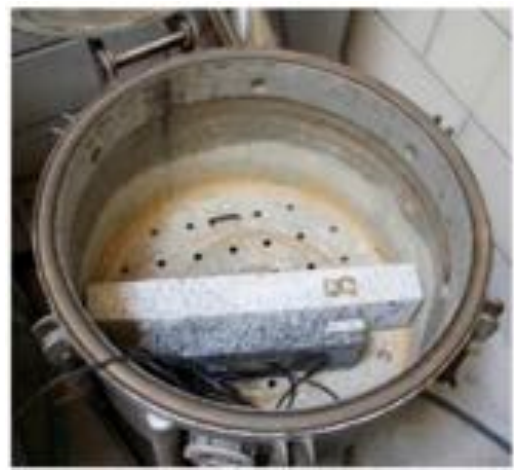

(b)

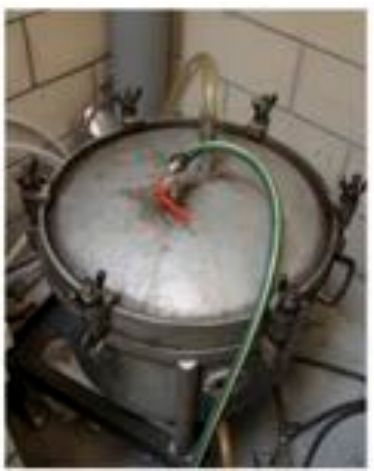

(c)

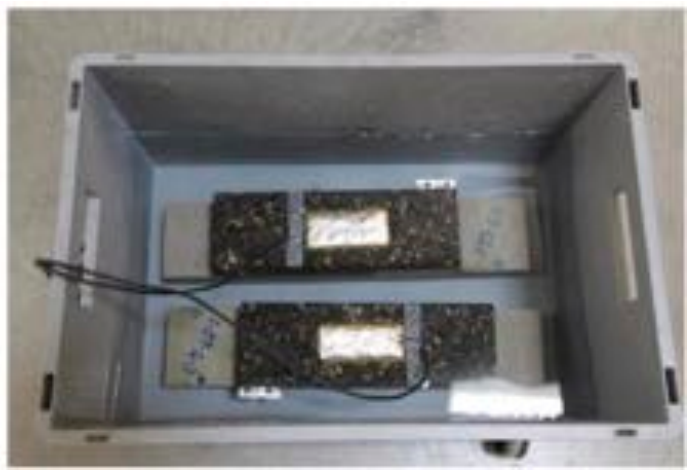

Figure 5. The bi-layer specimen preparation for the water saturation process (From (Hun, 2012)): (a) The specimen placed in the air vacuum box; (b) The air vacuum box closed; (c) The water container in which the specimens are conditioning before the test

(a)

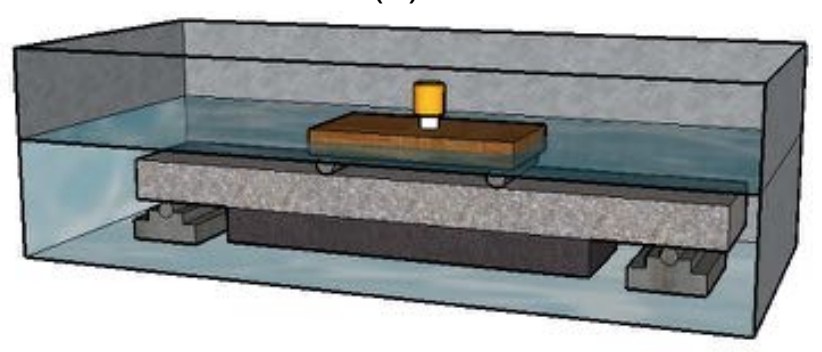

(b)

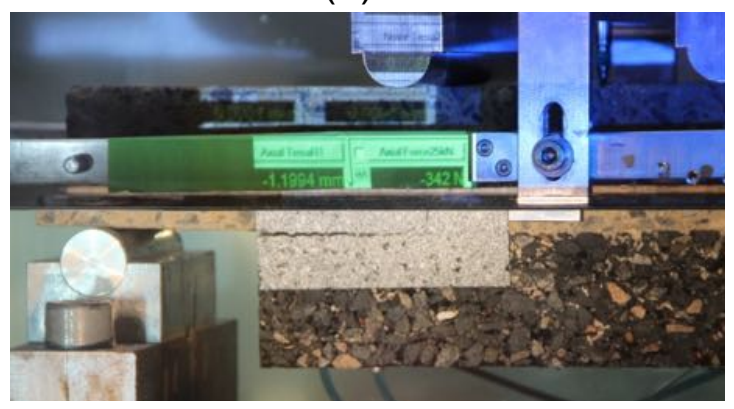

Figure 6. The experimental device of the $4 \mathrm{pt}$ bending test: (a) The aquarium used as a climatic chamber with and without water and LVDT sensor location; (b) General view of the DIC zone and of the loading force value displayed on the device (end of the I-PT-6-2 test) 

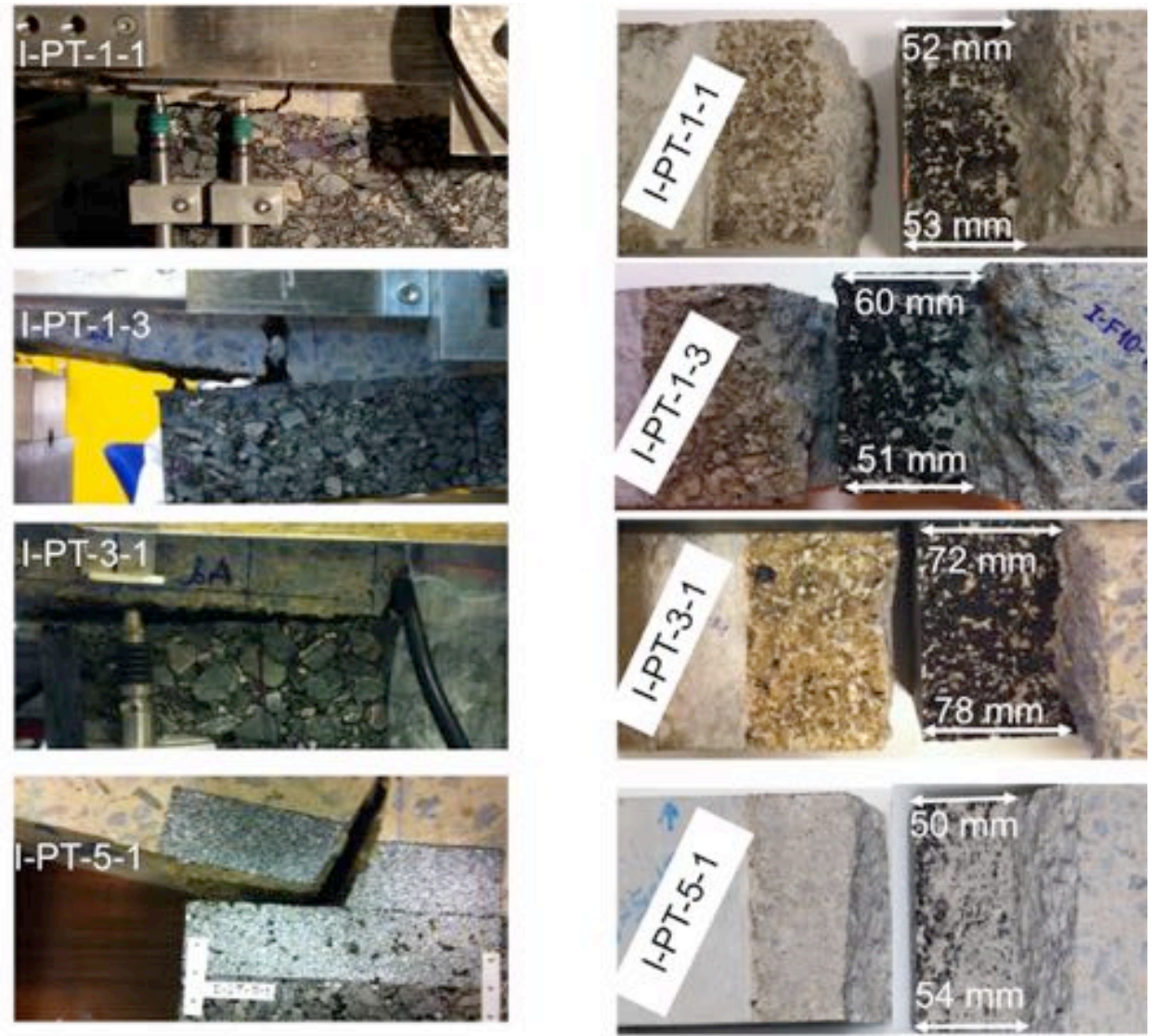

Figure 7. Visual debonding fracture aspect (lateral and top views) of the 4 specimens tested in dry condition
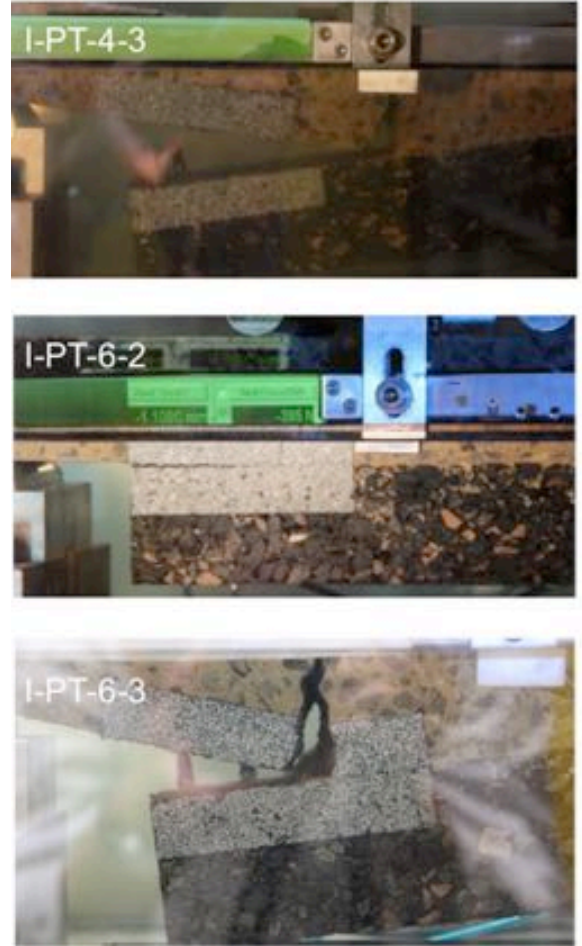

Figure 8. Visual debonding fracture aspect (lateral and top views) of the 3 specimens tested in the water bath 


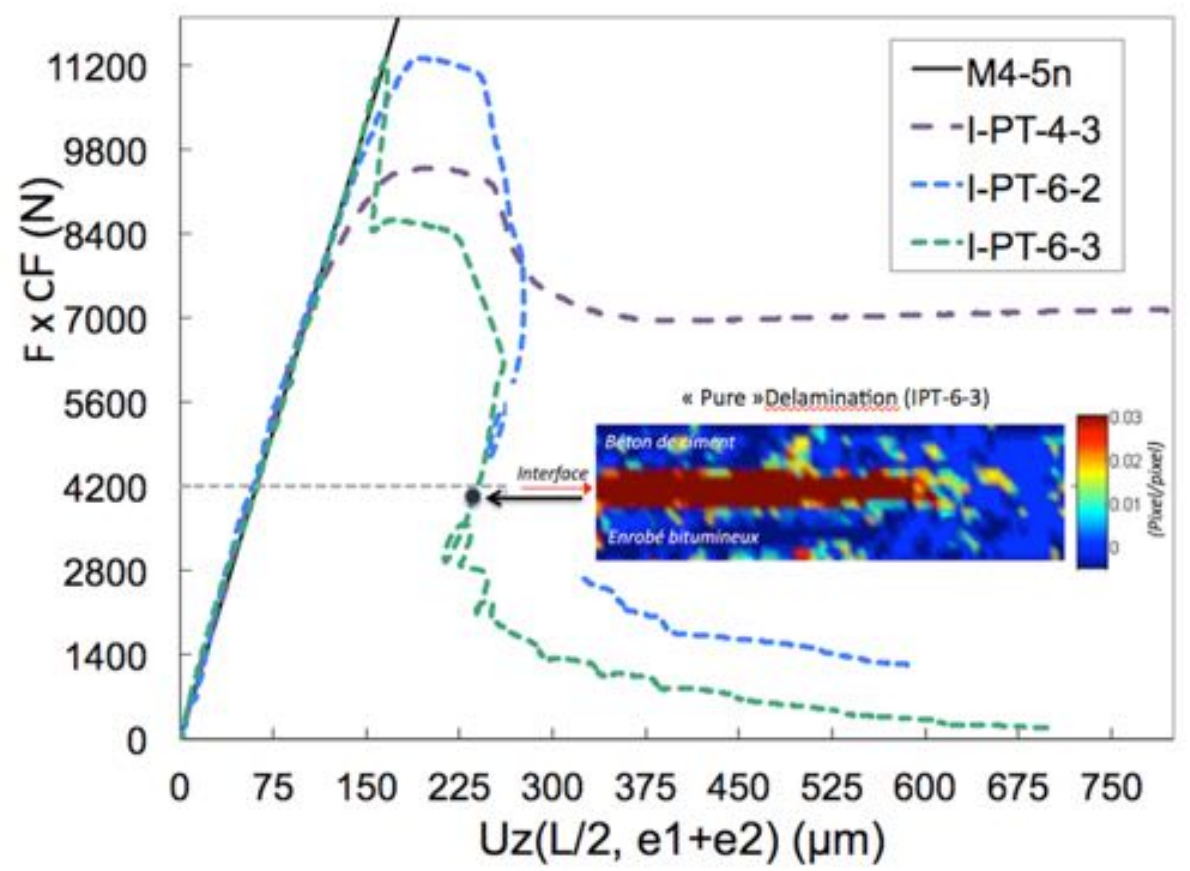

Figure 9. Force-displacement curves and one DIC illustration of bi-layer specimens tested into the water bath

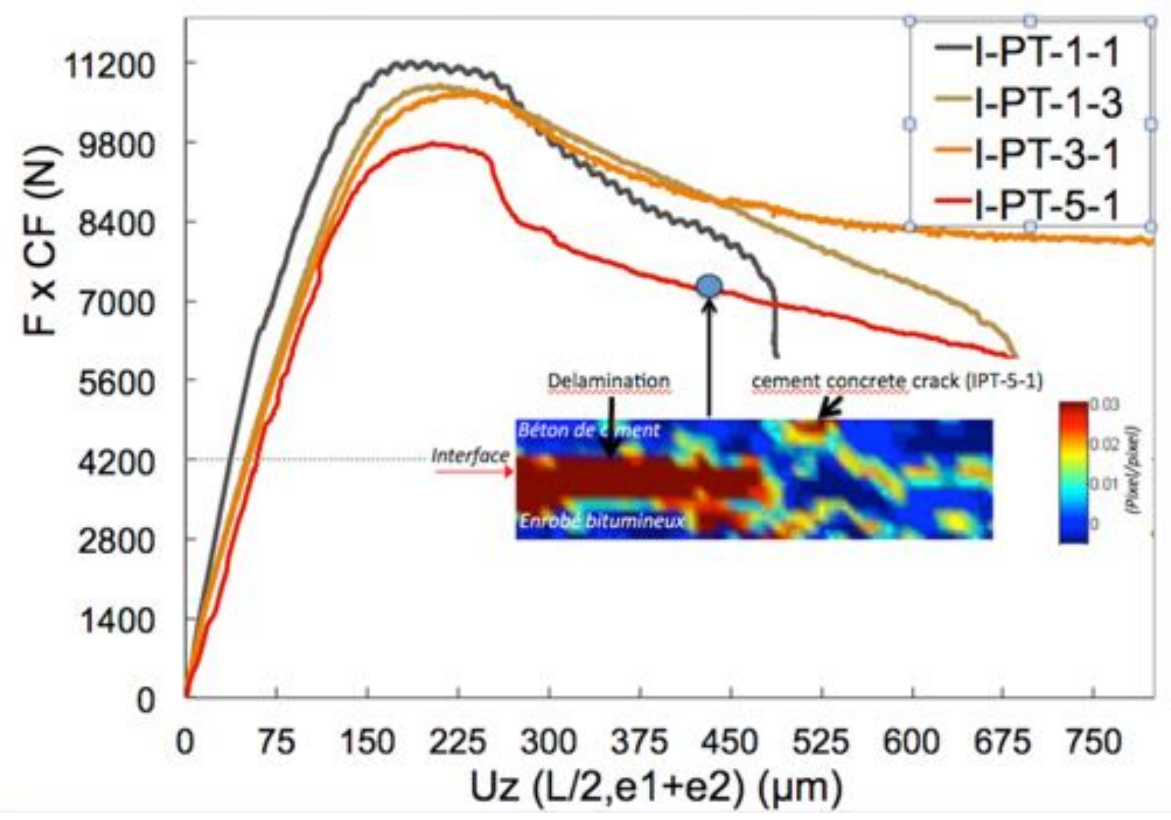

Figure 10. Force-displacement curves and one DIC illustration for bi-layer specimens tested in dry condition and presenting a final failure of debonding 
(a)

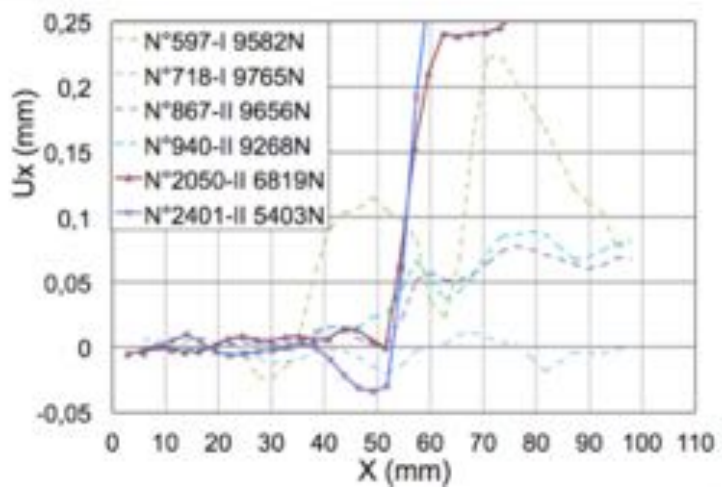

(b)

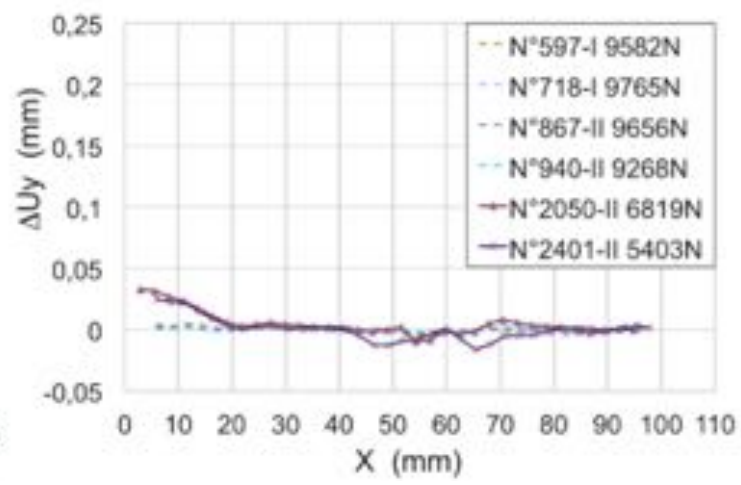

Figure 11. DIC displacement results of the IPT 5-1 specimen (dry condition): (a) Transversal displacement at the bottom of the cement concrete layer (b) Differential of vertical displacements between layers 1 and 2

(a)

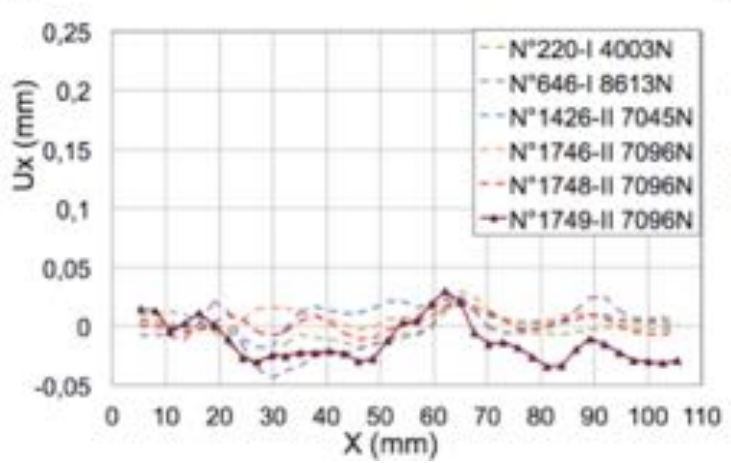

(b)

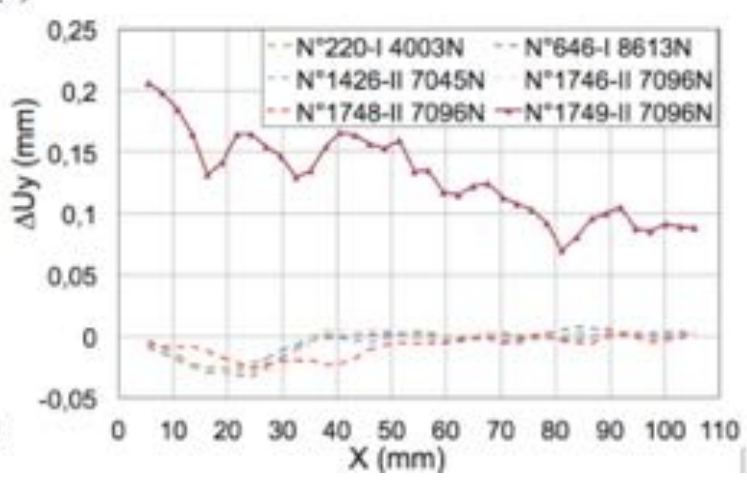

Figure 12. DIC displacement results of the IPT 4-3 specimen (dry condition): (a) Transversal displacement at the bottom of the cement concrete layer (b) Differential of vertical displacements between layers 1 and 2

(a)

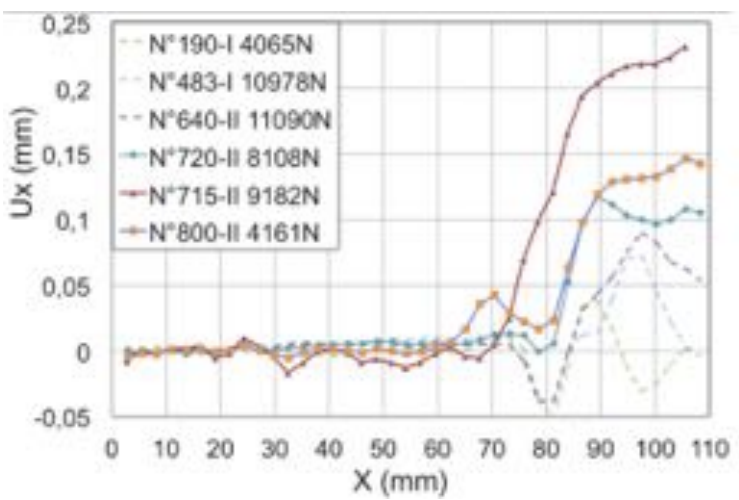

(b)

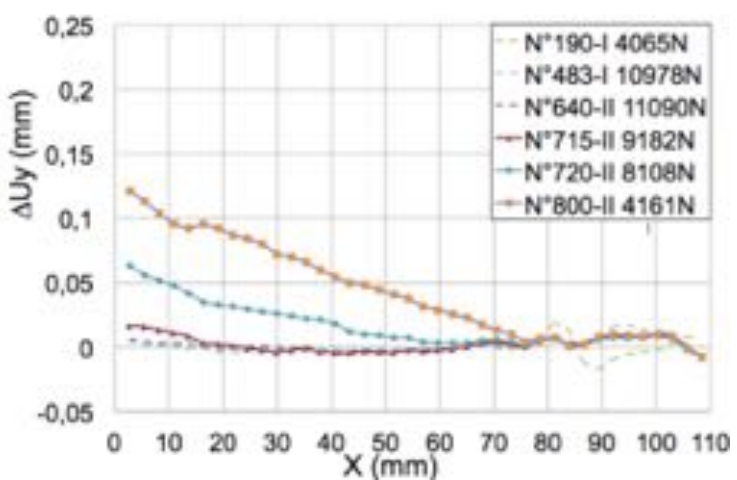

Figure 13. DIC displacement results of the IPT 6-2 specimen (dry condition): (a) Transversal displacement at the bottom of the cement concrete layer (b) Differential of vertical displacements between layers 1 and 2 
(a)

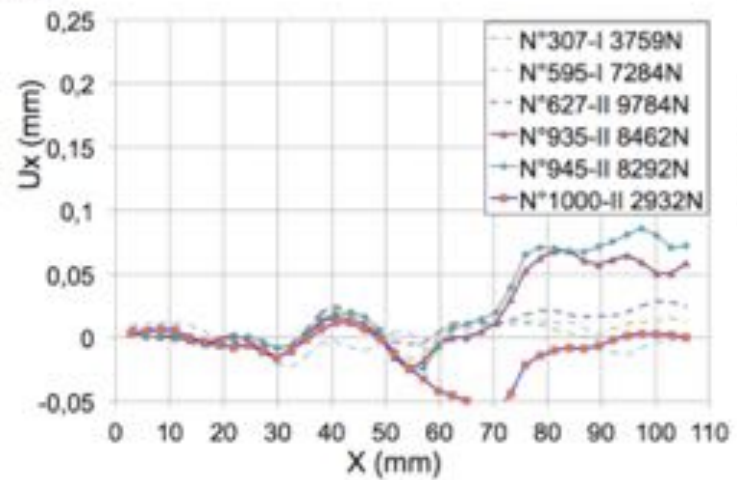

(b)

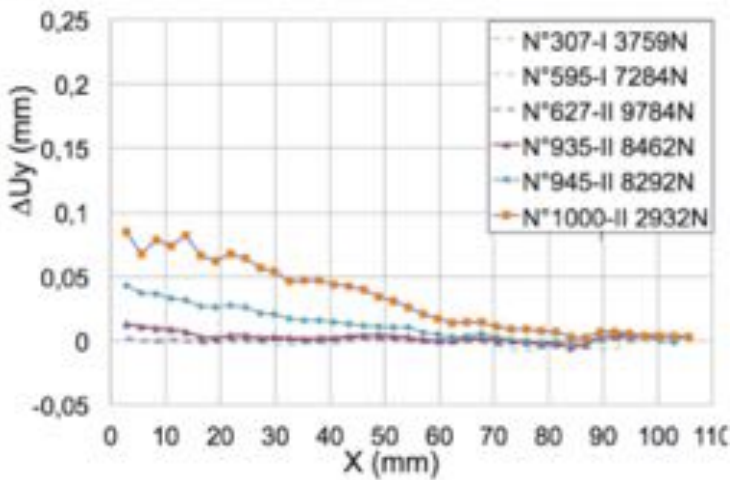

Figure 14. DIC displacement results of the IPT 6-3 specimen (dry condition): (a) Transversal displacement at the bottom of the cement concrete layer (b) Differential of vertical displacements between layers 1 and 2 